\title{
Educación y Espacio Público en la experiencia histórica reciente de Chile: El caso de la transformación neoliberal y autoritaria del sistema educacional durante la Dictadura Militar (1973-1990)
}

Educação e Espaço Público na experiência histórica recente do Chile: o caso da transformação neoliberal e autoritária do sistema educacional durante a Ditadura Militar (1973-1990)

Education and Public Space in the recent historical experience of Chile: the case of the neoliberal and authoritarian transformation of the educational system during the Military Dictatorship (1973-1990)

FELIPE ANDRES ZURITA GARRIDO ${ }^{1}$

\section{Resumen}

Este artículo tiene como objetivo analizar algunas transformaciones sufridas por el sistema educacional chileno durante la Dictadura Militar (1973-1990), desde la perspectiva de la mutación del papel desempeñado por el Estado en el campo educacional. Para lograr dicho objetivo se siguen los siguientes pasos: en un primer momento, se caracteriza el sistema educacional chileno vigente hasta 1973. En un segundo momento, se analizan algunas Políticas Públicas Educacionales de orientación neoliberal diseñadas e implementadas por el equipo económico de la Dictadura Militar. Finalmente, se proponen conclusiones con respecto a los impactos de las acciones desarrolladas por la Dictadura Militar sobre el sistema educacional y el profesorado, resaltando un cuestionamiento en torno a la modificación de la comprensión oficial de lo educativo en el espacio público.

Palabras clave: Políticas Públicas Educacionales; Dictadura Militar; Chile.

\footnotetext{
${ }^{1}$ Doctor en Educación por la Universidad Federal de Minas Gerais (Brasil). Profesor e Investigador de la Escuela de Pedagogía en Historia y Ciencias Sociales de la Facultad de Pedagogía de la Universidad Academia de Humanismo Cristiano (Chile). E-mail: fzurita@academia.cl; felipe_zuritag@yahoo.es.
} 


\title{
Resumo
}

Este artigo tem como objetivo analisar algumas transformações sofridas pelo sistema educacional chileno durante a Ditadura Militar (1973-1990), na perspectiva da mutação do papel desempenhado pelo Estado no campo educacional. Para atingir este objetivo, seguem-se os seguintes passos: num primeiro momento, é caracterizado o sistema educacional chileno em vigor até 1973. Em um segundo momento, são analisadas algumas Políticas Públicas Educacionais de orientação neoliberal desenhadas e implementadas pela equipe econômica da Ditadura Militar. Finalmente, são propostas conclusões sobre os impactos das ações desenvolvidas pela Ditadura Militar sobre o sistema educacional e o corpo docente, destacando um questionamento sobre a modificação do entendimento oficial da educação no espaço público.

Palavras-chave: Políticas Públicas Educacionais; Ditadura Militar; Chile.

\begin{abstract}
This article aims to analyze some transformations suffered by the chilean educational system during the Military Dictatorship (1973-1990), from the perspective of the mutation of the role played by the State in the educational field. To achieve this goal, the following steps are followed: Initially, the chilean education system in force until 1973 is characterized. In a second moment, some neoliberal-oriented Educational Public Policies designed and implemented by the economic team of the Military Dictatorship are analyzed. Finally, conclusions are proposed regarding the impacts of the actions developed by the Military Dictatorship on the educational system and the teaching staff, highlighting a questioning about the modification of the official understanding of education in public space.
\end{abstract}

Keywords: Public Educational Policies; Military Dictatorship; Chile. 


\section{El sistema educacional chileno vigente hasta 1973.}

La Constitución de 1833 tiene tres aspectos vinculados a la educación que apuntan al mismo concepto. El derecho a sufragio fue censitario, tanto como en la Constitución liberal, pero agregó como requisito "saber leer y escribir". La primera disposición transitoria suspendía esa condición por una década. Ella era también un nuevo concepto. Si en la Constitución anterior "poseer una ciencia", es decir, pertenecer al mundo letrado, era una cualidad que permitía el derecho a sufragio, señalar como requisito ser alfabeto llevaba implícito que la escuela debía cumplirlo. El aplazamiento se debió, precisamente, a la falta de estas. Ello le daba carácter constitucional a la relación entre ciudadanía y escritura, como la tenía con la propiedad. Esta relación, a su vez, se vincula con los dos artículos tan conocidos según los cuales la educación era una atención preferente del gobierno y la creación de una superintendencia de educación pública encargada de su inspección y dirección. Aunque no se ha interpretado de esta manera, a nuestro juicio, ello sintetiza la relación entre educación, ciudadanía política, república representativa y la unidad moral y política republicana. La Constitución del 33 estableció el Estado docente. Curiosamente, la más conservadora de las constituciones organizó jurídicamente la educación pública que luego los sectores políticos, educacionales e historiográficos, que se consideraron progresistas, reivindicaron como un triunfo del liberalismo sobre el conservadurismo. (SERRANO; PONCE DE LEÓN; RENGIFO, 2012, p. 85-86).

Sol Serrano, Macarena Ponce de León y Francisca Rengifo (2012) sostienen la tesis de que el Estado Docente en Chile habría sido fundado por la facción triunfadora de la Batalla de Lircay (1830) que después se constituyó en Gobierno y dio vida a la llamada República Conservadora (1830-1861). Dicha fundación del Estado Docente habría sido realizada, según las autoras, a través de la imbricación entre la condición de alfabetizado y el derecho político al voto presente en la Constitución de 1833, lo que habría establecido una señal clara en la dirección de cierta obligación del Estado de Chile de crear un sistema educacional que facilitaría la alfabetización de la población. Esta hipótesis, además de interesante, es perfectamente posible de acompañar, no en la línea de asumir que los diferentes grupos políticos e intelectuales que dieron sustento a la República Conservadora estuviesen interesados en construir y ampliar un sistema educacional para incorporar efectivamente a amplios sectores en la definición de los asuntos públicos, sino, en la línea de señalar que finalmente la inauguración del Estado Docente se oficializó en la Constitución de 1833 donde el Estado fue indicado como responsable preferente de la educación y que esto finalmente fue asumido por Gobiernos de diferente tendencias políticas e ideológicas, estableciéndose como una tradición de orientación republicana de larga data en la experiencia chilena. 
De esta forma, el Estado Docente, entendido como la hegemonía del Estado en la creación, dirección, financiamiento y ampliación del sistema educacional, se materializó a través de un vendaval de publicación de cuerpos legales, inauguración de instituciones, importación de propuestas pedagógicas y formación de nuevos actores educacionales, los que en un diálogo no siempre sencillo fueron dándole vida a un amplio y demandado socialmente sistema educacional de carácter fundamentalmente público y estatal.

Ya bien entrada la segunda mitad del Siglo XX es posible señalar la plena vigencia del Estado Docente mediante la revisión de algunas Políticas Públicas Educacionales de los Gobiernos anteriores a la Dictadura Militar, las que serían marcadas por dos grandes movimientos: modernización y democratización.

En el caso de la Política Educacional del Gobierno de Eduardo Frei Montalva ${ }^{2}$ se llevó a cabo un amplio proceso de Reforma Educacional, sustentando teóricamente en los principios del "Planeamiento Integral de la Educación". En el plano de la modernización educacional, se llevó adelante un amplio proceso de Reforma Educacional ${ }^{3}$ que implicó una transformación en el Plan de Estudios ${ }^{4}$, del Currículum Nacional ${ }^{5}$ y los Programas de Estudios correspondientes. (Berchenko, 1983). Para viabilizar estas transformaciones a través de un cuerpo docente capacitado, poseedor de conocimientos y técnicas pedagógicas modernas, se creó el Centro de Perfeccionamiento, Experimentación e Investigaciones Pedagógicas (CPEIP) ${ }^{6}$, que centró sus actividades en la conformación de un equipo de técnicos e investigadores educacionales dedicados al diseño e implementación de programas de perfeccionamiento y reciclaje dirigidos a docentes. Según Berchenko (1983) por primera vez en la historia de Chile, una institución estatal tenía la capacidad de poner a disposición de un número importante del Profesorado una oportunidad de perfeccionamiento, alcanzando los siguientes niveles de cobertura: 1967: 8.000 docentes; 1968: 5.869 docentes; 1969: 15.290 docentes.

En el plano de la democratización, durante el Gobierno de Eduardo Frei Montalva se alcanzaron notables mejorías con respecto a los indicadores de matrícula escolar ${ }^{7}$, retención escolar y acceso a un grupo de programas de carácter asistencial, que ayudaron a generar condiciones mínimas para el mejoramiento de los indicadores educacionales. En esta última

\footnotetext{
${ }^{2}$ Para acceder a un análisis amplio de la Política Educacional del Gobierno de Eduardo Frei Montalva, además, de la mano de un educador que trabajó en el diseño e implementación de la Reforma Educacional de 1965, se recomienda revisar: LEYTON, M. La experiencia chilena: la reforma educacional: 1965-1970. Santiago: CPEIP, 1970. 417 p.

${ }^{3}$ CHILE. Decreto N ${ }^{\circ} 27.952$ Modifica Sistema Educacional. Ministerio de Educación Pública, Santiago, 20 Diciembre 1965. Disponible en: http://bcn.cl/1mxwz. Consultado en: 14 Julio 2015.

${ }^{4}$ Hasta ese momento la estructurada del sistema escolar contemplaba dos periodos: 6 años de Preparatoria y 6 años de Humanidades. Con la Reforma de 1965 se pasó a la siguiente organización: 8 años de Educación General Básica y 4 años de Educación Media.

${ }^{5}$ Desde el punto de vista curricular, se habría definido una organización de las disciplinas escolares en base a los principios de gradualidad, integración y flexibilidad, con un énfasis transversal puesto en el desarrollo del conocimiento y experimentación del método científico. (Berchenko, 1983).

${ }^{6}$ CHILE. Ley $\mathrm{N}^{\circ}$ 16.617 Fija escala de categorías, grados y sueldos de los funcionarios que indica. Crea la Corporación denominada Servicio de Bienestar del Magisterio y de los funcionarios dependientes del Ministerio de Educación Pública. Dispone fondos para diversas instituciones. Modifica impuestos. Modifica leyes y decretos con fuerza de ley que señala. Aprueba disposiciones varias. Otras materias. Ministerio de Hacienda, Santiago, 31 Enero 1967. Disponible en: http://bcn.cl/1tryb Consultado en: 14 Julio 2015.

${ }^{7}$ La matrícula en Educación General Básica habría pasado de una cobertura de 1.350.000 estudiantes en 1964 a 2.000.000 de estudiantes en 1970. (Berchenko, 1983).
} 
línea, un papel importante lo jugó la creación de la Junta Nacional de Auxilio Escolar y Becas $(\text { JUNAEB })^{8}$, que logró sistematizar y modernizar los esfuerzos públicos de asistencia a estudiantes ya existentes.

En el caso de la Política Educacional del Gobierno de la Unidad Popular ${ }^{9}$, se puede señalar que se desarrolló un gran esfuerzo de democratización de la enseñanza (Pedro Castro, 1977; Pablo Berchenko, 1983; Iván Núñez; 2003) en una doble dimensión:

a) Cuantitativa: se amplió el ingreso ${ }^{10}$ y permanencia de estudiantes en todos los niveles educacionales, a través de la eliminación de barreras que dificultaban las mismas, tales como la eliminación del pago de matrícula para ingresar a la Enseñanza Media, como así también, a partir del aumento de la asistencialidad dirigida a ayudar a las y los estudiantes (becas, alimentación, salud) y del equipamiento de las instituciones educativas públicas (compra de materiales pedagógicos, maquinarias y edificación escolar). Estas medidas, apuntaban a favorecer el acceso a oportunidades educacionales a segmentos mayores de la población, especialmente a aquellos sectores históricamente marginados de las mismas. (Iván Núñez, 2003).

b) Cualitativa: se trabajó con miras a vincular el sistema educacional al proceso de transformaciones político/sociales de la vía chilena al socialismo. De esta manera, se entendía que la educación ya no podría seguir funcionando de la misma manera en que lo venía haciendo, tendría que abrirse al proceso de transformaciones democráticas, enfrentando una nueva perspectiva de definición del poder en lo educativo. En esta línea, se impulsaron las siguientes acciones: involucración de los trabajadores de la educación en la dirección de la Política Educacional ${ }^{11}$; realización de un debate nacional sobre la realidad educacional que desembocó en el Congreso Nacional de Educación (13 a 16 de Septiembre de 1971); elaboración del Decreto de Democratización que proponía un proceso de descentralización del poder en la escuela, proponiendo una nueva organización ${ }^{12}$ de la misma, donde la comunidad y diversas organizaciones participaran en su organización y

\footnotetext{
${ }^{8}$ CHILE. Ley $N^{\circ} 15.720$ Crea una corporación autónoma con personalidad jurídica y derecho público y domicilio en Santiago, denominada Junta Nacional de Auxilio Escolar y Becas. Ministerio de Educación Pública, Santiago, 01 Octubre 1964. Disponible en: http://bcn.cl/1ngre Consultado en: 14 Julio 2015.

${ }^{9}$ Para una acceder a un análisis más específico de la Política Educacional del Gobierno de la Unidad Popular se recomienda revisar: GONZÁLEZ, F. La educación de masas, por las masas y para las masas: El programa de la Unidad Popular y la escuela como espacio de lucha política. Pacarina del Sur. Revista de Pensamiento Crítico Latinoamericano. México D. F., n 17, Octubre-Diciembre 2013; GONZÁLEZ, F.; OSANDÓN, L. La educación de masas durante la Unidad Popular: una nueva escuela para toda la comunidad. In: PINTO, J. Fiesta y drama. Nuevas historias de la Unidad Popular. Santiago: LOM, 2014. p. 109-142.

${ }^{10} \mathrm{El}$ indicador de aumento de las matrículas en los diversos niveles de enseñanza es el siguiente: a) Pre-Básica: 1970) 60.370 estudiantes - 1973) 79.363; b) Educación General Básica: 1970) 2.200.160 estudiantes - 1973) 2.322.730 estudiantes; c) Educación Media: 1970) Científico Humanista 202.506 estudiantes / Técnico Profesional 99.558 estudiantes - 1973) Científico Humanista 282.721 estudiantes / Técnico Profesional 163.141 estudiantes; d) Educación Superior: 1970) 76.979 estudiantes - 1973) 145.663 estudiantes. Ver: COX, C.; JARA, C. Datos básicos para la discusión de políticas en educación. 1970-1988. Santiago: CIDE / FLACSO, 1989. 74 p.

${ }^{11}$ En esta línea, fue significativo el nombramiento del Vicepresidente del Sindicato Único de Trabajadores de la Educación, Mario Astorga Gutiérrez, como Ministro de Educación en el primer gabinete del Presidente Salvador Allende.

${ }^{12}$ Se proponía la articulación de diferentes instancias de decisión y poder ejecutivo, con representación de la comunidad, organizaciones y trabajadores de la educación, a nivel territorial (Consejo Regional de Educación, Consejo Provincial de Educación, Consejo Local de Educación) y dentro de la escuela (Consejo de Comunidad Escolar, Consejo de Trabajadores de la Educación, Comité Directivo).
} 
dirección ${ }^{13}$; exposición al debate público de la Escuela Nacional Unificada (ENU) que proponía una nueva organización de la escuela, intentando unificar los diferentes niveles educacionales (Educación Básica y Educación Media) en una nueva estructura (Educación General y Politécnica) que favoreciese su recorrido, y que a la vez, rompiera con algunas ideas fuerza de la educación tradicional, favoreciendo la vinculación del proceso de enseñanza/aprendizaje con el trabajo productivo, ayudando así a superar la división entre trabajo manual y trabajo intelectual.

Con respecto al Profesorado, Iván Núñez (1982) presenta una perspectiva condensada sobre el Trabajo Docente en Chile anterior al 1973. Un primer aspecto a considerar tendría que ver con la innegable relevancia "social y educacional del sector docente". Dicha relevancia, sería posible de ser graficada en las dimensiones cuantitativa y cualitativa. Con respecto a la dimensión cuantitativa, Iván Núñez (1982) señala que el Profesorado se presentaba como “(...) uno de los agrupamientos socio-laborales más numerosos del país” (Página 1). Hacía 1973, el "sector docente” estaría integrado por unas 90.000 trabajadoras y trabajadores, correspondiendo a un $14,8 \%$ de los trabajadores del sector terciario y a un $20 \%$ de los funcionarios de la administración pública. En una dimensión cualitativa, Iván Núñez (1982) fundamenta la relevancia del "sector docente" en los siguientes aspectos: ser parte de un Sistema Nacional de Educación en expansión y altamente demandado; surgir de un proceso de formación docente "antiguo y calificado" que sustentaría su condición profesional; alcanzar una temprana condición de gremio organizado; ser parte importante del movimiento sindical debido a su importante número y participación; tener un importante peso político debido a su influencia electoral, importancia social, influencia en las comunidades y ser fuente de formación de líderes políticos; ser fundamental en el desarrollo educacional, tanto a nivel de las aportaciones individuales de algunos de sus miembros más calificados, como también más colectivamente por su participación en la definición de las Políticas Públicas Educacionales.

La sucinta revisión de las Políticas Públicas Educacionales de estos dos Gobiernos y de algunas características del Trabajo Docente del periodo 1964-1970, permite sostener algunas observaciones: Primero, es notorio que la imagen de Estado que sostiene estas regulaciones, es aquella del Estado Docente, que asume la responsabilidad de dirigir, fomentar, financiar y organizar al sistema educacional, gracias al trabajo de un amplio cuerpo de técnicos, funcionarios y profesionales que hacen viables dichas tareas, como así también, gracias al convencimiento de que la educación sería un derecho social a materializar de forma creciente e ineludible para toda la población. El Estado Docente, se refleja en aspectos cruciales del sistema educacional chileno de este periodo: la propiedad y administración de las instituciones educacionales públicas recaían en el Ministerio de Educación Pública; la mayor parte de la matrícula escolar se encontraba en instituciones de carácter público ${ }^{14}$; el

\footnotetext{
${ }^{13}$ Finalmente, después de un extenso proceso de discusión y enfrentamiento entre el Ministerio de Educación Pública y la Contraloría General de la República, careció de los elementos más transformativos de la organización de las instituciones educacionales, restableciendo la autoridad de los directivos unipersonales y limitando la capacidad democratizadora de la iniciativa. (Iván Núñez, 2003).

${ }^{14}$ La matrícula escolar ubicaba en instituciones educacionales de dependencia pública alcanzaba en 1970 un 78,5\% de la matrícula total, mientras que en 1973 alcanzaba un 78,1\% de la misma. (Cristián Cox y Cecilia Jara, 1989, página 12).
} 
financiamiento estatal en educación era alto y de primera importancia ${ }^{15}$, existía una institucionalidad pública que definía y orientaba la Política Pública Educacional, entre otros. Otro aspecto importante, dice relación con la imagen de un Estado Docente que asume la tarea de ampliación de la matrícula en todos los niveles del sistema educacional como una vía lógica de democratización de la sociedad. En esta línea, se puede sostener que en el Chile de 1970 sí existía un consenso con relación a la legitimidad y validez de cierta tradición histórica que visualizaba a la educación como un derecho social, que debía materializarse con mayores niveles de profundidad que antaño. También es cierto, que la educación debía expandirse lo más ampliamente posible, debido a que esta era asumida como una vía de modernización económica/social de la sociedad. Ahí es posible comprender el consenso político en torno a la perspectiva de la Educación Permanente, puesto que si bien, esta portaba una consigna democratizadora, que ponía el acento en la ampliación de las capacidades humanas en diferentes momentos de la existencia vital de las personas, a la vez, se estaba pensando también en el fortalecimiento de la capacidad productiva de la población que iría a posibilitar el ocupar un lugar concreto de la economía nacional en un mercado de creciente alcance mundial. Planteado de esta forma, ya sea como vía de democratización o de modernización económica, o ambas de la mano, es innegable que para los dos Gobiernos del periodo 19641973 la educación se visualizó como un espacio vital en la articulación de sus proyectos de sociedad, independientemente de sus particulares diferencias doctrinarias y perspectivas teleológicas.

Una tercera observación, dice relación con el carácter específico del Trabajo Docente en la lógica de un Estado Docente. En base a la revisión precedente sería posible sostener que el Trabajo Docente en el Chile de 1973 se caracterizaría por vivenciar una situación ambivalente y tensionada por diversos fenómenos: a) poseer de forma mayoritaria un estatuto laboral de funcionario público, que le imprimía toda una perspectiva de protección/estabilidad/ascenso asegurado por el Estado; b) poseer un nivel formativo adecuado y en tendencia al mejoramiento, considerando la presión ejercida por el aumento de la matrícula escolar; c) poseer remuneraciones históricamente limitadas, no obstante, en proceso de mejoramiento; d) poseer una amplia y vital vinculación/compromiso/actuación con respecto a los grandes procesos de orden político que se desarrollan en Chile, además, donde su aporte sería de una alta importancia e impacto; e) ser parte activa de un proceso de abierta expansión del sistema educacional, situando su actividad en un alto sitial de relevancia social; f) poseer una tradición histórica de organización gremial/política legitimada socialmente y efectiva al momento de impactar la realidad nacional; g) formarse en una red de instituciones educacionales de larga tradición; h) ser la cara del Estado en ampliación, que llegaba más y mejor a lugares/sujetos tradicionalmente excluidos. Iván Núñez (1990) caracteriza a la relación entre el Trabajo Docente y el Estado bajo la nomenclatura de "integración conflictiva", puesto que en un plano se necesitaban y apoyaban mutuamente, mientras que en

${ }^{15}$ El gasto público en educación alcanzó los siguientes porcentajes del Producto General Bruto de Chile: 1970: 4,18\%; 1971: 5,28\%; 1972: 5,72\%; 1973: 4,29\%. Este mismo gasto público en educación, alcanzó los siguientes porcentajes del gasto fiscal total: 1970: 15,6\%; 1971: 17,3\%; 1972: 18,8\%; 1973: 10,1\%. (Cristián Cox y Cecilia Jara, 1989, página 6). Observando estas cifras, resulta evidente un fenómeno de aumento sostenido del gasto público en educación, que se ve interrumpido en el año 1973, debido a las diferentes dificultades que atravesaba la sociedad chilena en torno al creciente y radicalizado fenómeno de enfrentamiento político/social que derivó en el Golpe de Estado del 11 de Septiembre. 
otro plano, se hacía necesario dar paso a un enfrentamiento/conflicto constante. Recogiendo esta argumentación, se podría señalar que en el primer plano habría existido un consenso en torno a una opción de liderazgo político/económico estatal de tipo desarrollista/modernizador/industrializador, como así también, en torno a la opción de expansión educacional de orientación pública con protección al Trabajo Docente. Mientras que, entendiendo y compartiendo lo señalado anteriormente, para el Profesorado era necesario e irrenunciable llevar adelante una política gremial de presión al Estado por mejoras materiales de su actividad y por una profundización de las políticas educacionales de extensión/democratización educacional. Ambas fuerzas, apoyo/conflicto, marcaban la relación entre este Estado Docente y el Trabajo Docente, eso sí, en un contexto de reglas político/laborales claras, de orientación democrático/republicanas.

Revolución, Desarrollo, Modernización y Democratización son algunos de los aspectos claves que marcan a las Políticas Públicas Educacionales y al Trabajo Docente en el Chile anterior a la Dictadura Militar, donde además, el Estado (Estado Docente) era visualizado por diferentes (nuevos y antiguos) agrupamientos políticos, como una herramienta de transformación profunda de la realidad, en un ambiente institucional de organización/distribución del poder político de carácter democrático y republicano. El derrotero trágico de este fenómeno, de intento de ampliación de la cara transformacional de la realidad política/social/educacional, mostró finalmente, que debajo de la frágil envoltura institucional (democrática y republicana) se cocinaba el descontento de aquellos grupos que veían pavoridos, con una expresión desfigurada por el terror, como el Chile de su secular propiedad se veía amenazado por extensas ansias de mudanza. Finalmente, una violenta ebullición de ese descontento despertó temprano a ese Chile que buscaba cambiar, durante una mañana de invierno, era el martes 11 de Septiembre de 1973.

\section{La transformación neoliberal.}

A fines de la década de 1970 la Dictadura Militar comenzó a institucionalizar una serie de profundas transformaciones, las llamadas Siete Modernizaciones ${ }^{16}$, que harían posible reorientar la capacidad productiva de Chile hacia un nuevo lugar dentro del sistema capitalista bajo la egida del Modelo Neoliberal. En términos muy específicos, esto implicó una salida del Estado de la propiedad, oferta y gestión de diversos servicios (derechos) y espacios de regulación que históricamente venía asumiendo como una responsabilidad ineludible. De esta forma, se comenzó a diseñar e implementar Políticas Públicas en diversos planos, que tenían la característica común de disminuir a niveles paupérrimos el financiamiento público, incentivando el ingreso de privados a ofertar y competir en la venta de bienes y servicios a la población, dejando en la lógica del mercado la solución de amplias necesidades sociales y económicas. En el área de educación esto se mostró de manera clara con la publicación, en marzo de 1979, del documento llamado Directiva Presidencial sobre la Educación Nacional que se constituiría en el faro orientador de una serie de Políticas Públicas Educacionales de

\footnotetext{
${ }^{16} \mathrm{El}$ conjunto de las amplias y profundas regulaciones fundadas en principios neoliberales fueron definidas por la Dictadura Militar como las "Siete Modernizaciones", a saber: Plan Laboral; Reforma del Sistema Previsional; Directiva Presidencial de la Educación; Reforma del Sistema de Salud; Reforma Administrativa; Modernización del Sector Agrícola; Reforma del Sistema de Justicia.
} 
marcado corte Neoliberal. En dicho documento se proponían amplios objetivos y se comprometía una fecha específica y cercana para la realización de estudios técnicos y elaboraciones jurídicas, con miras a implementar las mismas. Iván Núñez (1982) presenta la siguiente mirada general sobre los objetivos que señalaba este documento:

contracción del esfuerzo educacional del Estado y privatización creciente de la enseñanza; universalización de la educación básica combinada con la selectividad de la educación media y superior; diversificación del sistema educativo; reorganización profunda de la educación superior, etc.; todo ello presidido por el marco ideológico oficial contenido en la Declaración de Principios de la Junta de Gobierno y el llamado Objetivo Nacional (NÚÑEZ, 1982, p. 32).

Esta perspectiva general se condice completamente con la carta pública que Augusto Pinochet dirigió al Ministro de Educación Pública de entonces, el historiador y abogado Gonzalo Vial Correa, acompañando la Directiva Presidencial sobre la Educación Nacional (1979). En dicha carta, Augusto Pinochet le hizo saber al Ministro de Educación Pública los aspectos fundamentales contenidos en la propuesta de reorientación educacional, donde además de aquellos de orden doctrinario (guía del humanismo cristiano en la orientación educacional) se presentaron otros novedosos y reveladores. El primero de estos aspectos fundamentales, tiene que ver con la aceptación pública de la inexistencia de una voluntad de expandir la acción del Estado en materia educacional, legitimando así el necesario y destacado nuevo rol del "sector privado" dentro del sistema educacional chileno:

3) La posibilidad que el Estado expanda aún más su labor educacional debe considerarse improbable, atendidas la magnitud alcanzada por aquélla, la escasez de recursos, la urgencia de emplearlos en consolidar la obra ya realizada en este campo, y la existencia de otras necesidades sociales, también prioritarias. Por consiguiente, se estimulará con energía la ayuda que el sector privado presta a la tarea educacional (PINOCHET, 1979, p. 2).

En las palabras de Augusto Pinochet Ugarte, si el Estado no expandiría su acción en materia educacional en términos amplios, como venía ocurriendo en los Gobiernos anteriores a la Dictadura Militar, por lo menos sí se comprometía a trabajar intensivamente en desarrollar la Educación Básica, eso sí, visualizando la formación de un perfil de chilenos específico:

4) El Estado centrará el énfasis de la educación básica y, a cualquier costo, cumplirá su deber histórico y legal de que todos los chilenos, no sólo tengan acceso a ella sino que efectivamente la adquieran y así queden capacitados para hacer buenos trabajadores, buenos ciudadanos y buenos patriotas (PINOCHET, 1979, p. 2). 
Considerando el compromiso de asegurar el desarrollo de la Educación Básica para la población, los siguientes niveles educacionales asumieron desde aquí un carácter abiertamente excluyente, puesto que se accedería a ellos cumpliendo algunas exigencias difíciles de alcanzar para una parte importante de la población:

5) Alcanzar la educación media y en especial, la superior, constituye una situación de excepción para la juventud, y quienes disfruten de ella deben ganarla con esfuerzo - lo cual implica un alto nivel de trabajo y exigencia compatibles con los avances científicos y tecnológicos - y además debe pagarse o devolverse a la comunidad nacional por quienes puedan hacerlo ahora o en el futuro. El que recibe gratuitamente una educación que puede pagar o no restituye su valor cuando esté ello a su alcance, priva de legítimas oportunidades educacionales a otros chilenos. (PINOCHET, 1979, p. 2).

De esta manera, mediante la Directiva Presidencial sobre la Educación Nacional (1979) se imprimió al proceso de regulación del sistema educacional chileno una impronta de abierto retroceso de la concepción de educación como derecho, en tanto el Estado justifica la reducción de su papel de financiador; posibilita el ingreso de capital privado al sistema educacional; legitima una propuesta educacional mediocre y excluyente al limitar el acceso a la Educación Media y Educación Superior a la población, utilizando los cuestionables criterios de capacidad económica y capacidad académica.

Lo señalado hasta aquí es completamente coherente con el lugar asignado a la educación en la Constitución Política de la República de Chile creada en el seno de la Dictadura Militar y publicada finalmente el 24 de Octubre de $1980^{17}$. Dentro del Título III de los derechos y deberes constitucionales dos artículos son dedicados a la educación:

$10^{\circ}$. El derecho a la educación. La educación tiene por objeto el pleno desarrollo de la persona en las distintas etapas de su vida. Los padres tienen el derecho preferente y el deber de educar a sus hijos. Corresponderá al Estado otorgar especial protección al ejercicio de este derecho. La educación básica es obligatoria, debiendo el Estado financiar un sistema gratuito con tal objeto, destinado a asegurar el acceso a ella de toda la población. Corresponderá al Estado, asimismo, fomentar el desarrollo de la educación en todos sus niveles; estimular la investigación científica y tecnológica, la creación artística y la protección e incremento del patrimonio cultural de la Nación. Es deber de la comunidad contribuir al desarrollo y perfeccionamiento de la educación. (CHILE, 1980, p. 1).

$11^{\circ}$. La libertad de enseñanza incluye el derecho de abrir, organizar y mantener establecimientos educacionales. La libertad de enseñanza no

\footnotetext{
${ }^{17}$ CHILE. Decreto Supremo N 1.150 Constitución Política de la República de Chile. Ministerio del Interior, Santiago, 24 Octubre 1980. Disponible en: http://bcn.cl/1wb8d Consultado en: 14 Julio 2015.
} 
tiene otras limitaciones que las impuestas por la moral, las buenas costumbres, el orden público y la seguridad nacional. La enseñanza reconocida oficialmente no podrá orientarse a propagar tendencia político partidista alguna. Los padres tienen el derecho de escoger el establecimiento de enseñanza para sus hijos. Una ley orgánica constitucional establecerá los requisitos mínimos que deberán exigirse en cada uno de los niveles de la enseñanza básica y media y señalará las normas objetivas, de general aplicación, que permitan al Estado velar por su cumplimiento. Dicha ley, del mismo modo, establecer los requisitos para el reconocimiento oficial de los establecimientos educacionales de todo nivel. (CHILE, 1980, p. 1).

El Artículo $\mathrm{N}^{\circ} 10$ sobre el Derecho a la Educación es claro al asignar a "los padres" la responsabilidad de educar a "sus hijos", lo mismo que en el Artículo $11^{\circ}$ sobre Libertad de Enseñanza, donde "los padres" tienen el derecho de escoger dónde educar a "sus hijos". Este esquema de palabras no es accidental, puesto que lo que procura es encapsular en la esfera íntima de las familias, o sea, en la esfera privada, fuera del alcance de la acción pública, el secreto del mecanismo dónde se define la organización del sistema educacional chileno. Ya no es el Estado organizando, gestionando y ofertando educación a la población, ahora el problema se reduce a decisiones de "los padres" sobre sus "hijos". En el mismo Artículo $10^{\circ}$, el Estado se dibuja como un "protector" de este derecho de "los padres" de educar a "sus hijos", eso sí, en un esquema de amplía e flexible Libertad de Enseñanza señalado en el Artículo $11^{\circ}$, donde "los padres” tendrán la amplia libertad de elegir entre múltiples alternativas educacionales, para "sus hijos". En dicho esquema, se entiende el lugar reducido y pragmático asignado para que la comunidad realice su aporte al desarrollo educacional. La Libertad de Enseñanza, de manera aclaradora, es básicamente conceptualizada en torno a principios de propiedad: "derecho a abrir, organizar y mantener establecimientos educacionales", que sólo reconocerán los límites puestos por "la moral, las buenas costumbres, el orden público y la seguridad nacional". La Constitución Política de la República de Chile (1980), otorgó el cimiento jurídico a la definición educacional ya advertida en la Directiva Presidencial sobre la Educación Nacional (1979), consagrando así la idea de Estado Subsidiario y el papel preponderante del sector privado en la educación chilena.

Una de las múltiples Políticas Públicas Educacionales elaboradas y fundamentadas en la Directiva Presidencial sobre la Educación Nacional (1979) y en la Constitución Política de la República de Chile (1980), además directamente vinculada con transformaciones en el Trabajo Docente, corresponde a la Municipalización del Sistema Escolar. La Dictadura Militar se asignó a sí misma la tarea de transformar profundamente las estructuras del país y la mentalidad de los chilenos. Una de las vías para alcanzar estos grandes objetivos fue la política de descentralización, que encontró sus canales de realización a través de sendos procesos de Descentralización Territorial ${ }^{18}$ y Descentralización Administrativa ${ }^{19}$, que

\footnotetext{
${ }^{18}$ CHILE. Decreto Ley N ${ }^{\circ} 575$ Regionalización del país. Ministerio del Interior, Santiago, 13 Julio 1974. Disponible en: http://bcn.cl/1vjwk Consultado en: 14 Julio 2015.
} 
lograron transformar la estructura de organización del territorio nacional y la estructura de distribución del poder político administrativo. Esta tarea fue liderada por la Comisión Nacional de Reforma Administrativa (CONARA) ${ }^{20}$ y se guio de manera deliberada bajo los principios de Subsidiaridad del Estado y de Descentralización del Poder ${ }^{21}$ :

En virtud del principio de subsidiariedad se postuló que el Estado sólo debe asumir aquellas actividades operativas que el sector privado, una vez otorgadas las condiciones necesarias, no tenga interés o capacidad de realizar directamente y que los niveles superiores no deben inmiscuirse en las facultades propias de los niveles inferiores, salvo que condiciones excepcionales así lo exijan. Se determinó, también, que el principio de descentralización del poder, en íntima relación con el de subsidiariedad, conlleva la descentralización administrativa orientada a radicar suficientes facultades, recursos humanos y materiales en los niveles político-administrativos regionales, provinciales y comunales. (CONARA, 1981, p. 5).

Es en este contexto de descentralización mayor que debe entenderse el proceso de Municipalización del Sistema Escolar Público o Fiscal. En el fondo, la pregunta que enfrentaban los gestores y asesores educacionales y económicos de la Dictadura Militar era cómo implementar el proceso de descentralización del Sistema Escolar, considerando que ya existían, desde 1967, las Coordinaciones Regionales de Educación:

Puede apreciarse, entonces, que durante 1979 se produce un cambio sustancial respecto al carácter que debiera asumir el proceso de descentralización de la administración educacional. En marzo, las Directivas Presidenciales enfatizan que la descentralización debería llevarse a cabo a través de los Servicios Provinciales de Educación. En julio se propone la idea de descentralización vía municipalidades. En diciembre se legisla sobre el traspaso de los servicios públicos a la esfera municipal. Pero todavía no se detallan los alcances ni los mecanismos de la "municipalización" ni se indica qué servicios serán traspasados. (PIIE, 1984, p. 124).

${ }^{19}$ CHILE. Ley N ${ }^{\circ} 18.575$ Orgánica Constitucional de Bases Generales de la Administración del Estado. Ministerio del Interior - Subsecretaria del Interior, Santiago, 05 Diciembre 1986. Disponible en: http://bcn.cl/1uvo7 Consultado en: 14 Julio 2015.

${ }^{20}$ CHILE. Decreto Ley $\mathrm{N}^{\circ} 212$ Crea Comisión Nacional de la Reforma Administrativa. Ministerio del Interior, Santiago, 26 Diciembre 1973. Disponible en: http://bcn.cl/1xzup Consultado en: 14 Julio 2015; CHILE. Decreto Ley $\mathrm{N}^{\circ} 2.093$ Modifica la naturaleza jurídica de la Comisión Nacional de Reforma Administrativa y fija planta de su personal. Ministerio de Hacienda, Santiago, 04 Enero 1978. Disponible en: http://bcn.cl/1xzur Consultado en: 14 Julio 2015.

${ }^{21}$ CONARA. Políticas de la Comisión Nacional de Reforma Administrativa, CONARA. Santiago: CONARA, 1981, 33 p. 
Con el Decreto con Fuerza de Ley $\mathrm{N}^{\circ}$ 1-3.063 de Junio de $1980^{22}$ se legisló finalmente sobre el traspaso de los Establecimientos Educacionales Públicos o Fiscales de Educación Básica y Educación Media desde el Ministerio de Educación Pública hacia las Municipalidades. Hacía 1980 existían 6.370 Establecimientos Educacionales Públicos o Fiscales de Educación Básica y Educación Media (Científico Humanista y Técnico Profesional) ${ }^{23}$ que atendían a 2.150.338 estudiantes $^{24}$, bajo la administración directa del Ministerio de Educación Pública. Con el proceso de Municipalización, estos Establecimientos Educacionales, estudiantes y docentes comenzaron a ser transferidos hacia alguna de las Municipalidades de las 336 Comunas existentes en la época ${ }^{25}$. El ritmo de este proceso de transferencia tuvo distintos momentos, marcados por las posibilidades y dificultades político-económicas que la Dictadura Militar enfrentó en esta etapa:

Este proceso de cambio de dependencia de los establecimientos educacionales, del Estado a entidades privadas y/o municipios, se realizó, principalmente, durante el periodo 1980-1981, en el que se traspasaron el $87 \%$ de las escuelas. Se culminó el proceso entre 19861989. Se habían detenido los traspasos entre 1982 y 1985, debido a la disminución del valor real de la subvención a partir de la crisis financiera de 1982 (MALDONADO, 2003, p. 7).

Lo interesante del análisis del Decreto con Fuerza de Ley $\mathrm{N}^{\circ} 1-3.063$ es que además de entregar la administración de los Establecimientos Educacionales Públicos o Fiscales a las Municipalidades, dejando de paso al Ministerio de Educación Pública sin escuelas que gestionar y abocado solamente a tareas de normalización y supervisión educacionales, abre la posibilidad legal de privatizar el sistema escolar. Uno de las formas que asumió esta posibilidad de privatización tiene que ver con la transformación de la condición laboral de las personas que se desempeñan en las Escuelas y Liceos traspasados:

Artículo $4^{\circ}$ - El personal perteneciente al organismo o entidad del sector público que se haya traspasado o se traspase a la Administración Municipal, y el que posteriormente se contrate para este servicio por la Municipalidad, no será considerado dentro de la dotación fijada para el municipio respectivo. Dicho personal se regirá en todo por las normas laborales, de remuneraciones y de previsión aplicables al sector privado. Al personal a que se refiere el inciso anterior, no le serán aplicables las normas de la legislación actual o

${ }^{22}$ CHILE. Decreto con Fuerza de Ley $N^{\circ}$ 1-3063 reglamenta aplicación inciso segundo del artículo $38^{\circ}$ del DL N ${ }^{\circ}$ 3.063, de 1979. Ministerio del Interior, Santiago, 13 Junio 1980. Disponible en: http://bcn.cl/pmd Consultado en: 14 Julio 2015.

${ }^{23}$ MALDONADO, M. La privatización de la educación en Chile. San José: Internacional de la Educación, 2003, 66 p.

${ }^{24}$ DÍAZ, J.; LÜDERS. R.; WAGNER, G. Chile 1810 - 2010. La República en cifras. Historical statistics. Santiago: Ediciones Universidad Católica de Chile, 2016, 780 p.

${ }^{25}$ CHILE. Decreto Ley N ${ }^{\circ} 2.868$ Divide las Provincias que señala del país en las Comunas que indica. Ministerio del Interior, Santiago, 26 Octubre 1979. Disponible en: http://bcn.cl/1w01b Consultado en: 14 Julio 2015. 
futura que rijan las remuneraciones del sector público. Los cargos que queden vacantes en el organismo del sector público por efecto del traspaso del personal se entenderán suprimidos y, si dicha entidad tenía fijada dotación máxima de personal, ésta quedará disminuida en el número de personas que se haya traspasado. (CHILE, 1980, p. 1).

De esta manera, el proceso de Municipalización significó la pulverización final de la frágil condición de empleado público del Profesorado ${ }^{26}$, puesto que se desvinculó al Trabajo Docente de la regulación establecida en el Estatuto Administrativo (1960) aún vigente. De esta manera, el Trabajo Docente fue quedando crecientemente expuesto a las condiciones regresivas y flexibles del Sistema Laboral Privado ${ }^{27}$; expuesto a las arbitrariedades de las orientaciones político-administrativas de Municipios que, durante toda la Dictadura Militar, fueron liderados por Alcaldes designados y de directa confianza del Régimen; expuestos a la inexistencia de condiciones laborales similares o básicas debido a las amplias diferencias económicas, administrativas y técnico-pedagógicas presentes en los diversos Municipios y sufriendo un profundo deterioro en sus remuneraciones:

Ello implicaba que el salario sería fijado de acuerdo a condiciones de mercado y que el profesor quedaba sujeto a la posibilidad de despido por motivo de disminución de la matrícula u otra causa contemplada en la legislación. En lo referente a las remuneraciones, este traspaso a las municipalidades significó la pérdida del sistema de ascensos y de calificaciones que existía desde 1978. Adicionalmente, los docentes municipalizados perdieron la asignación de título, la seguridad del pago de sus remuneraciones durante los períodos vacacionales, y la estructura de escalafones con sus correspondientes grados en la EUR. En definitiva, cada municipalidad debía decidir en cuanto a su realidad financiera las condiciones en que dejaría a su cuerpo docente. (ROJAS, 1998, p. 139).

\footnotetext{
${ }^{26}$ A los docentes se les ofrecía la posibilidad de A) continuar como Funcionario Público en otra dependencia educacional aún estatal o B) pasar al régimen de Trabajador Particular como condición previa a poder desempeñarse en un Establecimiento Educacional Municipalizado, opción que habría sido inducida mediante el pago de una indemnización por la ocurrencia del término de la condición de Funcionario Público. (Patricio Rojas, 1998).

${ }^{27}$ El Plan Laboral es la propuesta de organización de las relaciones entre Capital y Trabajo que la Dictadura Militar impuso hacía 1979. Las principales área de regulación establecidas en el Plan Laboral corresponden a la organización sindical y la negociación colectiva, marcadas por algunas de las siguientes características: limitar la negociación colectiva entre trabajadores y empresarios a los angostos límites de cada empresa, eliminando así la posibilidad de construir procesos de negociación a nivel de área productiva o regional/nacional; debilitar el efecto de presión de la huelga al permitir la existencia legal de reemplazantes; posibilidad de existencia de varios sindicatos o grupos de trabajadores habilitados al interior de cada empresa a negociar directamente con los empresarios; eliminar la actividad política al interior de los sindicatos. El gran artífice del Plan Laboral fue el economista José Piñera Echeñique, Ministro del Trabajo de la Dictadura Militar entre 1978 y 1980. El Plan Laboral es una de las denominadas Siete Modernizaciones de abierta orientación neoliberal impuestas por la Dictadura Militar. Ver: FUNDACIÓN SOL. Reforma Laboral. ¿Pone fin al Plan Laboral de la Dictadura o lo consolida? Infórmate, debate, propone. Santiago: Fundación Sol, 2015. 41 p.
} 
De esta manera, el proceso de Municipalización tuvo un impacto regresivo en la condición económica del Trabajo Docente, tanto por la pérdida de una serie de conquistas salariales alcanzadas a los largo de las décadas anteriores, como así también, por la pérdida de valor real de las remuneraciones percibidas. Algunas cifras que ayudan a ponderar esta situación son las siguientes:

GRÁFICO No 1: Remuneración Promedio Mensual Docentes (1960-1990) ${ }^{28}$

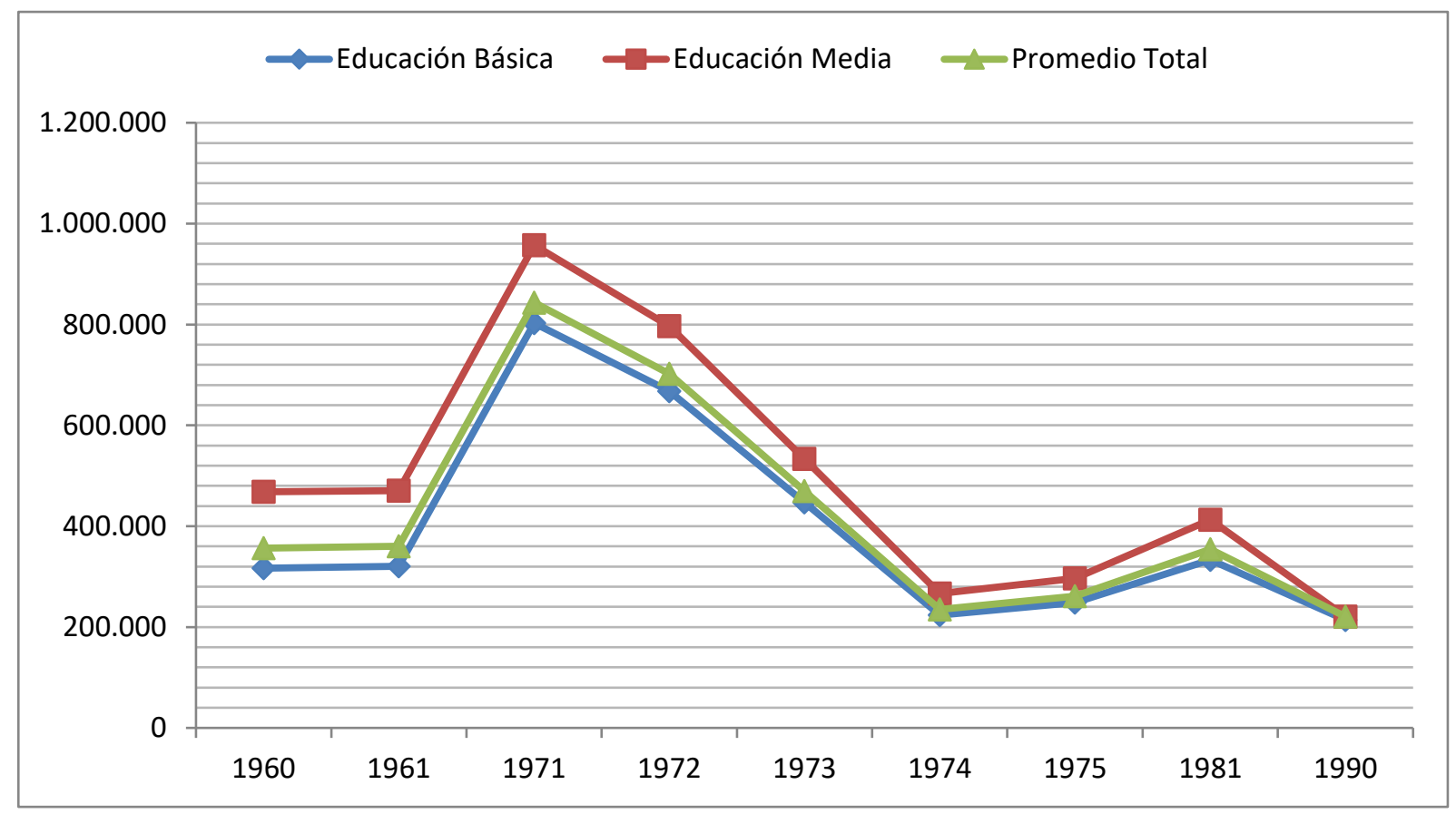

Fuente: ROJAS, P. Remuneraciones de los profesores en Chile. Estudio Públicos, Santiago, n.71, p.121-175, 1998.

En el Gráfico $\mathrm{N}^{\mathrm{o}} 1$ es posible observar una importante tendencia a la baja de la Remuneración Promedio del Profesorado chileno a partir del año 1971, momento en el que alcanza su punto más alto. Lo interesante de estos datos es que muestran que durante toda la Dictadura Militar la Remuneración Promedio del Profesorado no es capaz de superar el punto alcanzado hacía 1973, año marcado por una profunda convulsión política/económica, propia de los últimos momentos del Gobierno de la Unidad Popular. Además de lo anterior, es posible también señalar que en el punto más alto de la Remuneración Promedio alcanzado durante la Dictadura Militar (1981), apenas se llegó a marcar una superioridad marginal con respecto al año 1960-1961. Por otra parte, en este mismo Gráfico $N^{\circ} 1$ se entregan datos incompletos, fundamentalmente aquellos que aquí más interesan, o sea, el periodo que conforma el proceso de Municipalización (1980-1989). Patricio Rojas (1998) advierte que no es posible acceder a datos oficiales y comparables, puesto que además de la notoria pérdida del valor real de las Remuneraciones Docentes, a partir del proceso de Municipalización se generó un complejo e injusto proceso de diferenciación de Remuneraciones Docentes entre los diferentes Municipios, explicados finalmente por las evidentes diferencias económicas existentes entre estos, como así también, por las diferentes decisiones asumidas en materia

\footnotetext{
${ }^{28}$ Remuneración Promedio Mensual considerando una Jornada Completa de 44 Horas Semanales y calculada en pesos de Julio de 1997.
} 
educacional por parte de las nuevas autoridades educacionales de cada Municipio. En el Gráfico No 2, sólo a modo de muestra, se presentan las diferencias que existían hacía 1987 en las Remuneraciones Docentes dentro de un mismo Municipio según el Profesorado se desempañaba en un nivel o modalidad educacional, como así también, las diferencias que existían en las Remuneraciones Docentes en diferentes Municipios de una misma Región:

GRÁFICO No 2: Remuneraciones Brutas Mínimas y Máximas Docentes Sector Municipalizado Comunas Región Metropolitana de Santiago $(1987)^{29}$

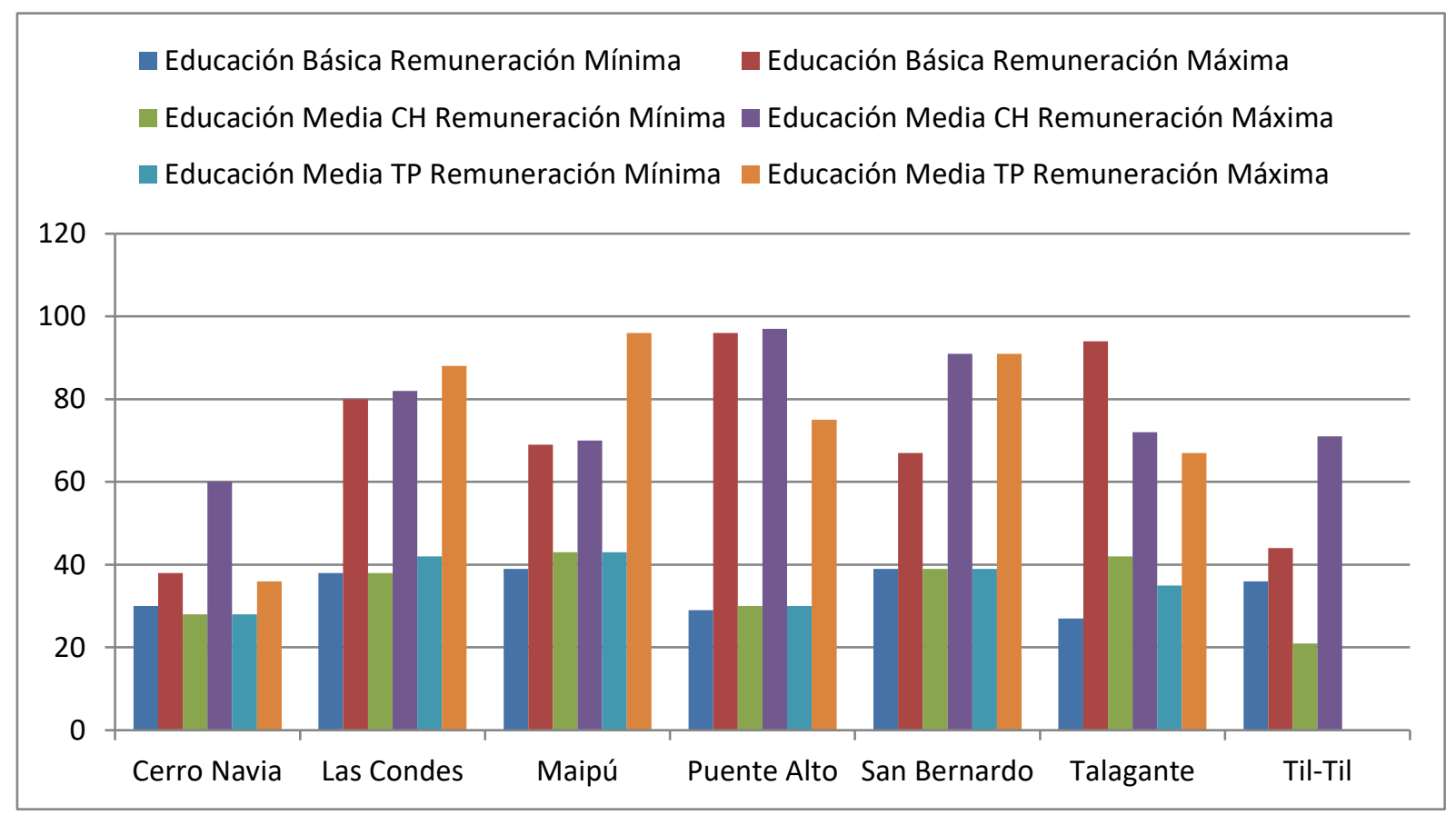

Fuente: COX, C.; JARA, C. Datos básicos para la discusión de políticas en educación. 1970-1988. Santiago: CIDE / FLACSO, 1989, 74 p.

Otra forma en que el proceso de Municipalización favoreció la privatización del sistema escolar corresponde a las posibilidades de gestión que se visualizó a través del Decreto con Fuerza de Ley $\mathrm{N}^{\circ} 1-3.063$ :

Artículo 12.- Las Municipalidades que tomen a su cargo servicios de las áreas de educación, de salud o de atención de menores, para los efectos de la administración y operación de ellos, podrán constituir, conforme a las normas del Título XXXIII del Libro I del Código Civil, con organizaciones de la comuna, interesadas en los servicios referidos, una o más personas jurídicas de derecho privado, o podrán entregar dicha administración y operación a personas jurídicas de derecho privado que no persigan fines de lucro. En los estatutos de las personas jurídicas que constituyan las Municipalidades deberá establecerse que la presidencia de ellas corresponderá al Alcalde respectivo, quien podrá delegarla en la persona que estime

\footnotetext{
${ }^{29}$ Remuneraciones calculadas en miles de pesos de 1987.
} 
conveniente y que el número de directores no podrá ser superior a cinco. Todos estos cargos serán concejiles. Autorízase a las Municipalidades que otorguen a la administración de los servicios referidos a personas jurídicas de derecho privado para entregarles en comodato los bienes inmuebles destinados a los servicios referidos, ya sean de propiedad de la Municipalidad o ésta los haya recibido, a su vez, en comodato para tales servicios. (CHILE, 1980, p. 1).

De esta forma, los Establecimientos Educacionales Municipalizados tendrían dos alternativas de institucionalidad posible para llevar adelante su gestión: A) Departamentos de Administración Educacional Municipal: que corresponde a una institucionalidad construida al interior de la Municipalidad y es regida para todos los efectos legales por el sistema jurídico de la administración pública y B) Corporaciones Privadas: que corresponde a personas jurídicas de derecho privado. De esta manera, si bien los Establecimientos Educacionales Municipales continuaban siendo de propiedad pública, su administración e infraestructura podía ser entregada a una institucionalidad privada. Lo interesante de este proceso de transferencia de responsabilidades educacionales al mundo privado es que el financiamiento continuó siendo público y centralizado, facilitando la viabilidad de la gestión de estos nuevos administradores educacionales:

Artículo 13.- Los recursos de origen fiscal o municipal que se destinen a las personas jurídicas de derecho privado a que se refiere el artículo anterior constituirán ingresos propios de ellas correspondientes a prestación de servicios. (...). Artículo 15.- La Contraloría General de la República fiscalizará las personas jurídicas de derecho privado a que se refiere el artículo 12, de acuerdo a las facultades que le otorga el artículo 25 de su Ley Orgánica. (CHILE, 1980, p. 1).

Esta modalidad de transferencia de la gestión de Establecimientos Educacionales Públicos o Fiscales al mundo privado también se dio en el mismo año 1980 de una manera más directa mediante la entrega de Establecimientos Educacionales Públicos de Educación Media Técnico Profesional a diferentes Gremios Empresariales, a través del Decreto Ley $\mathrm{N}^{\circ}$ 3.166 publicado el 06 de Febrero de $1980^{30}$. Estas transferencias se realizaron mediante la firma de convenios prorrogables en el tiempo, asegurando un sistema de financiamiento público a estas instituciones y la creación de Corporaciones de Administración Delegada por parte de los nuevos gestores. En el caso del Profesorado que se desempeñaba en estos Establecimientos Educacionales, al igual que en el caso del proceso de Municipalización, se vieron obligados a perder su condición de funcionarios públicos y a tener que optar por alguna de las siguientes salidas:

\footnotetext{
${ }^{30}$ CHILE. Decreto Ley N ${ }^{\circ} 3.166$ Autoriza entrega de la administración de determinados Establecimientos de Educación Técnico Profesional a las instituciones o a las personas jurídicas que indica. Ministerio de Educación Pública, Santiago, 06 Febrero 1980. Disponible en: http://bcn.cl/12sh Consultado en: 14 Julio 2015.
} 
Artículo $3^{\circ} \mathrm{El}$ personal de planta que servía en el establecimiento educacional respectivo y no continúe prestando servicios al Estado como consecuencia del traspaso, tendrá derecho a jubilar siempre que cuente con veinte o más años de imposiciones o de tiempo computable, de acuerdo con el artículo $12^{\circ}$ del decreto ley 2.448 , de 1979. Si no cumple con requisitos para acogerse a jubilación, tendrá derecho al beneficio que concede la letra e) del artículo $29^{\circ}$ del decreto ley 2.879, de 1979. Las horas de clase que servía y los cargos de las plantas del Ministerio de Educación Pública que ocupaba el personal que no siga prestando servicios al Estado, como consecuencia del traspaso del establecimiento respectivo, quedarán automáticamente suprimidos. (CHILE, 1980. p. 1).

Otra forma de privatización del Sistema Escolar, asociada en parte al proceso de Municipalización, tiene que ver con la conformación de un nuevo sistema de financiamiento elaborado en 1980. Mediante el Decreto Ley $N^{\circ} 3.476$ del 04 de Septiembre de $1980^{31}$ se estableció un sistema de financiamiento posible de ser definido como de "financiamiento a la demanda", en tanto se trata de una cantidad de dinero fijo que el Estado entrega a la institución gestora (Sostenedor) de un Establecimiento Educacional que haya sido elegido por las familias para educar a sus hijos, independientemente si la dependencia del mismo es Municipal, Particular Subvencionada o de Administración Delegada. Si bien, desde largo tiempo el Estado chileno entregaba recursos a Establecimientos Educacionales Particulares Gratuitos, siempre en una cantidad inferior a la entregada a los Establecimientos Educacionales Públicos o Fiscales bajo su dependencia y gestión, con el Decreto Ley $\mathrm{N}^{\circ}$ 3.476 los aportes a Establecimientos Educacionales se igualan en valor y comienzan a entregarse según un complejo esquema ${ }^{32}$ que privilegia la idea de que las familias puedan escoger dónde educar a sus hijos (Libertad de Enseñanza) al costo de entregar un tipo de financiamiento que no necesariamente tiene que ver con: las características específicas de cada Establecimiento Educacional y perfiles de estudiantes a atender; con el aseguramiento de condiciones materiales mínimas de infraestructura y disposición de material escolar; con el

${ }^{31}$ CHILE. Decreto Ley $N^{\circ} 3.476$ Fija normas a los establecimientos de enseñanza particular subvencionados por el Estado. Ministerio de Hacienda, Santiago, 04 Septiembre 1980. Disponible en: http://bcn.cl/1xivg Consultado en: 14 Julio 2015.

${ }^{32}$ Entre 1980-1987 se estableció un valor económico asociado a Unidades Tributarias Mensuales (UTM) que se actualizaba según el alza definida por el Índice de Precios al Consumidor (IPC). No obstante, debido al proceso de recesión económica a partir de 1982 el aumento del valor de las subvenciones deja de estar vinculados a las alzas del IPC, pasando a estar vinculada a los incrementos de las remuneraciones estipuladas para el sector público. A partir de 1987 se estableció un valor económico de medida denominado Unidad de Subvención Educacional (USE) que se actualizaba anualmente según los incrementos de las remuneraciones del sector público. Estos valores varían según el nivel (Educación Parvularia, Educación Básica, Educación Diferenciada, Educación Media) y modalidad (sin Jornada Escolar Completa o con Jornada Escolar Completa, Educación Media Científica Humanista o Educación Media Técnico profesional, Educación de Adultos) de enseñanza de cada Establecimiento Educacional. Considerando la USE la subvención se calcula considerando la cantidad de estudiantes matriculados y la asistencia efectiva promedio de los últimos tres meses. Con posterioridad, se han agregado otros criterios para incrementar la subvención de los Establecimientos Educacionales, tales como nivel de pobreza o dificultades de aprendizaje del estudiantado. (Espinoza y González, 1993). 
aseguramiento de condiciones materiales mínimas y homogéneas de remuneraciones del Trabajo Docente; con la articulación mínima de equipos de trabajo interdisciplinares para la mejor atención de las comunidades escolares; entre otras.

Esta modalidad de "financiamiento a la demanda", que crea la figura de un cupón o voucher educacional que genera la posibilidad virtual de favorecer la decisión de la familia de escoger una alternativa educacional, enfrentó serias dificultades en los primeros momentos de su implementación, debido a la pérdida de valor de la subvención establecida que se mantuvo a la baja durante la parte mayoritaria del proceso de Municipalización:

GRÁFICO No 3: Valor Subvención Anual por Estudiante (1970-1987) 33

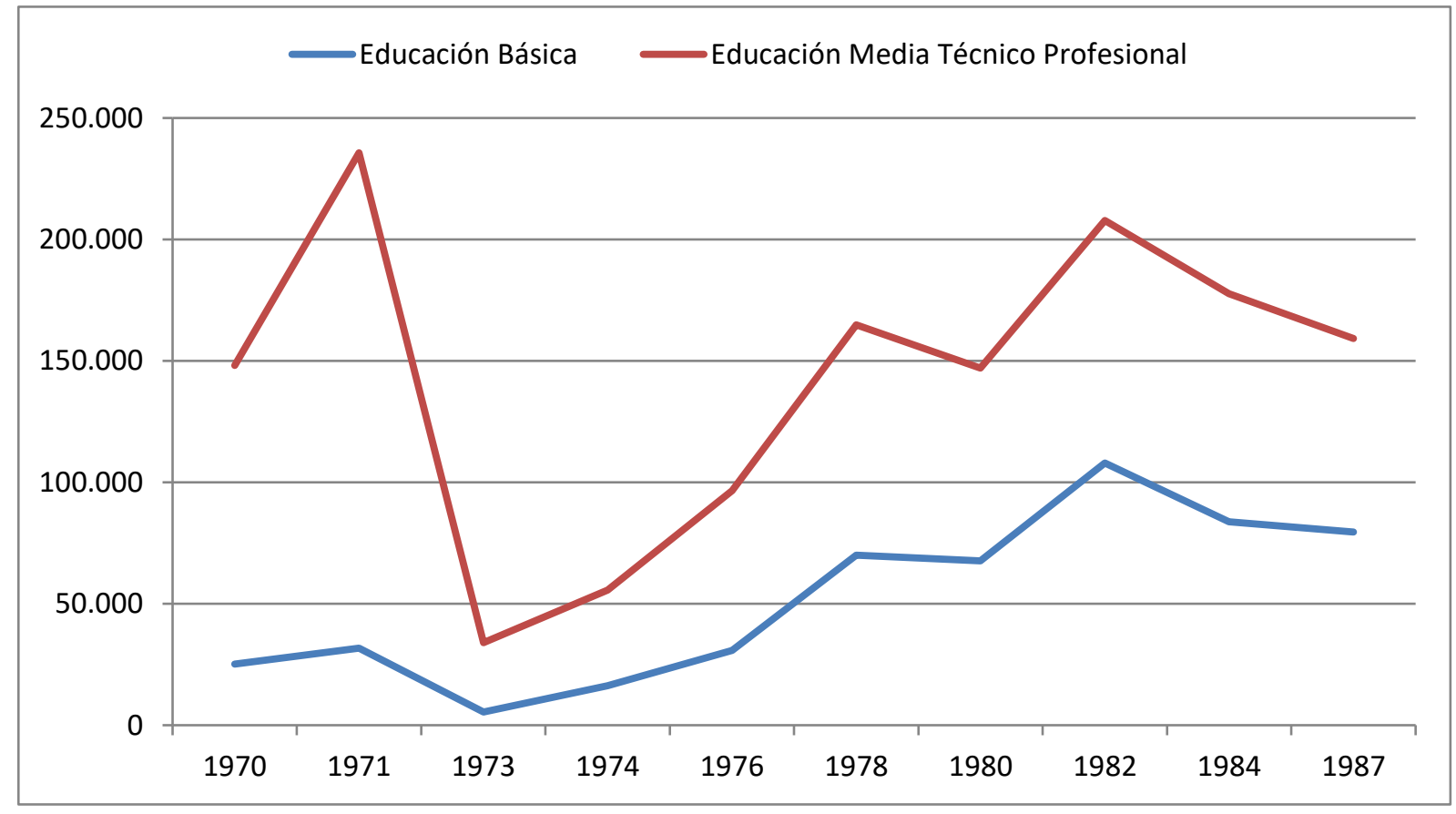

Fuente: ESPINOZA, O; GONZÁLEZ, L. La experiencia del proceso de desconcentración y descentralización educacional en Chile 1974-1989. Santiago: PIIE, 1993, 267 p.

La pérdida del valor económico de la subvención escolar, significó una paulatina disminución de recursos disponibles para la totalidad de los nuevos órganos de administración y gestión escolar: Departamentos de Administración Educacional Municipal o Corporaciones Privadas en el caso de los Establecimientos Educacionales Municipales; Corporaciones de Administración Delegada en el caso de los Establecimientos Educacionales de Educación Media Técnico Profesional traspasados a Gremios Empresariales; Sostenedor Particular en el caso de los Establecimientos Educacionales Particulares Subvencionados. En el caso de los órganos de gestión y administración de Establecimientos Educacionales Municipales se fue desenvolviendo un profundo proceso de déficit financiero, que limitó sus posibilidades de desarrollo y obligó al Gobierno a poner a su disposición una constante ayuda e intervención financiera (Espinoza y González, 2003):

\footnotetext{
${ }^{33}$ Valor de la Subvención calculado en Pesos de 1993.
} 
GRÁFICO No 4: Déficit Financiero en el Área Educación de las Municipalidades (1981-1985)

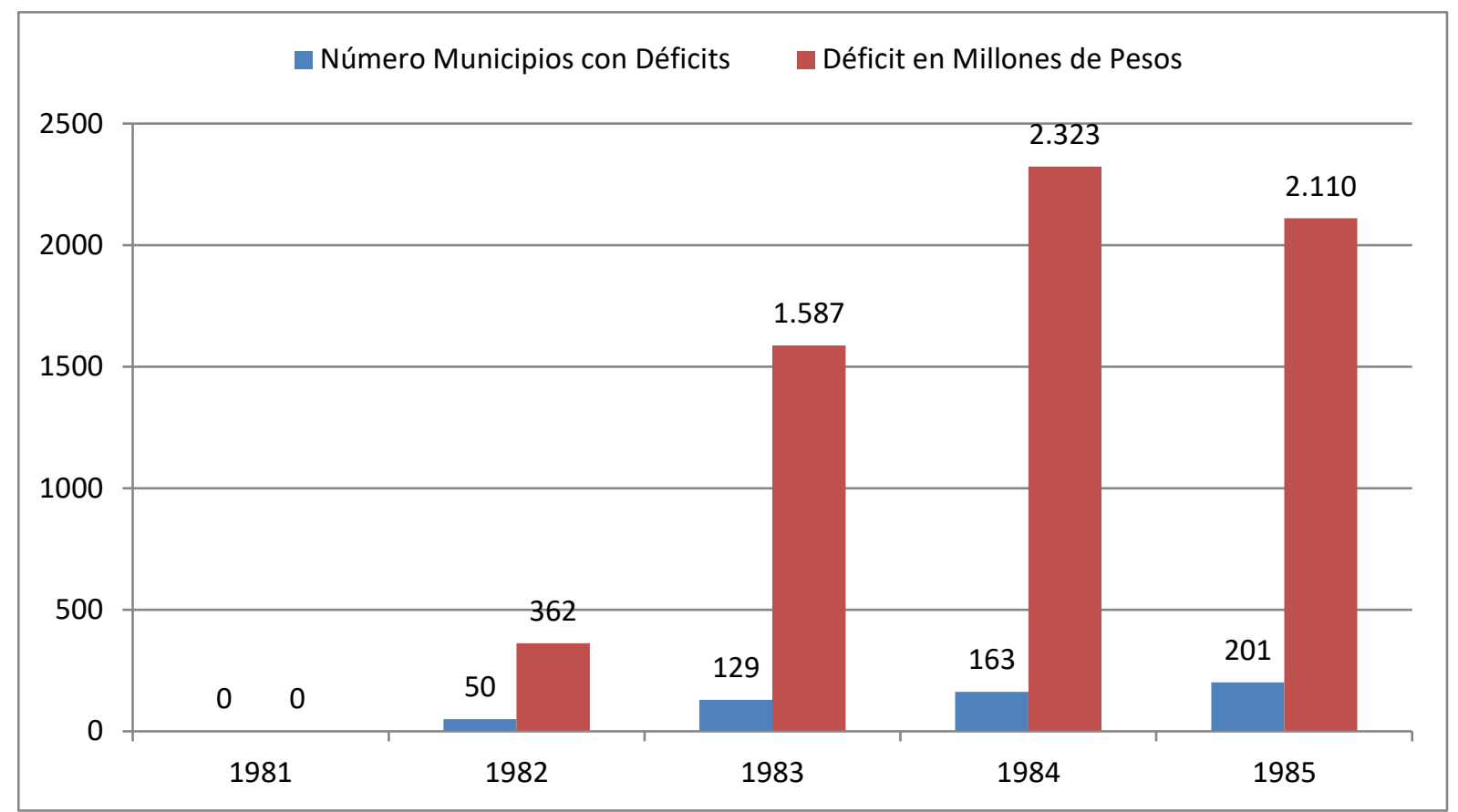

Fuente: ESPINOZA, O; GONZÁLEZ, L. La experiencia del proceso de desconcentración y descentralización educacional en Chile 1974-1989. Santiago: PIIE, 1993, 267p.

En el caso de los Establecimientos Educacionales, desde 1980 en adelante pasan a existir cuatro diferentes tipos de Dependencia Educacional a costa de la paulatina desaparición de la figura de Establecimiento Educacional Público o Fiscal. De esta manera, pasan a existir Establecimientos Educacionales Municipales, que tal como se señaló, siguen siendo propiedad del Estado, sin embargo, su administración puede ser llevada adelante por órganos públicos o privados; Establecimientos Educacionales gestionados por Corporaciones de Administración Delegada, que siguen siendo de propiedad del Estado, no obstante, son gestionados por Gremios Empresariales; Establecimientos Educacionales Particulares Subvencionados de propiedad privada, que al igual que los dos anteriores, son financiados por el Estado. Finalmente, los Establecimientos Particulares Pagados de larga existencia histórica y tradicionalmente vinculados a la formación de las elites: 
GRÁFICO N 5: Establecimientos Educacionales según Dependencia (1980-1990)

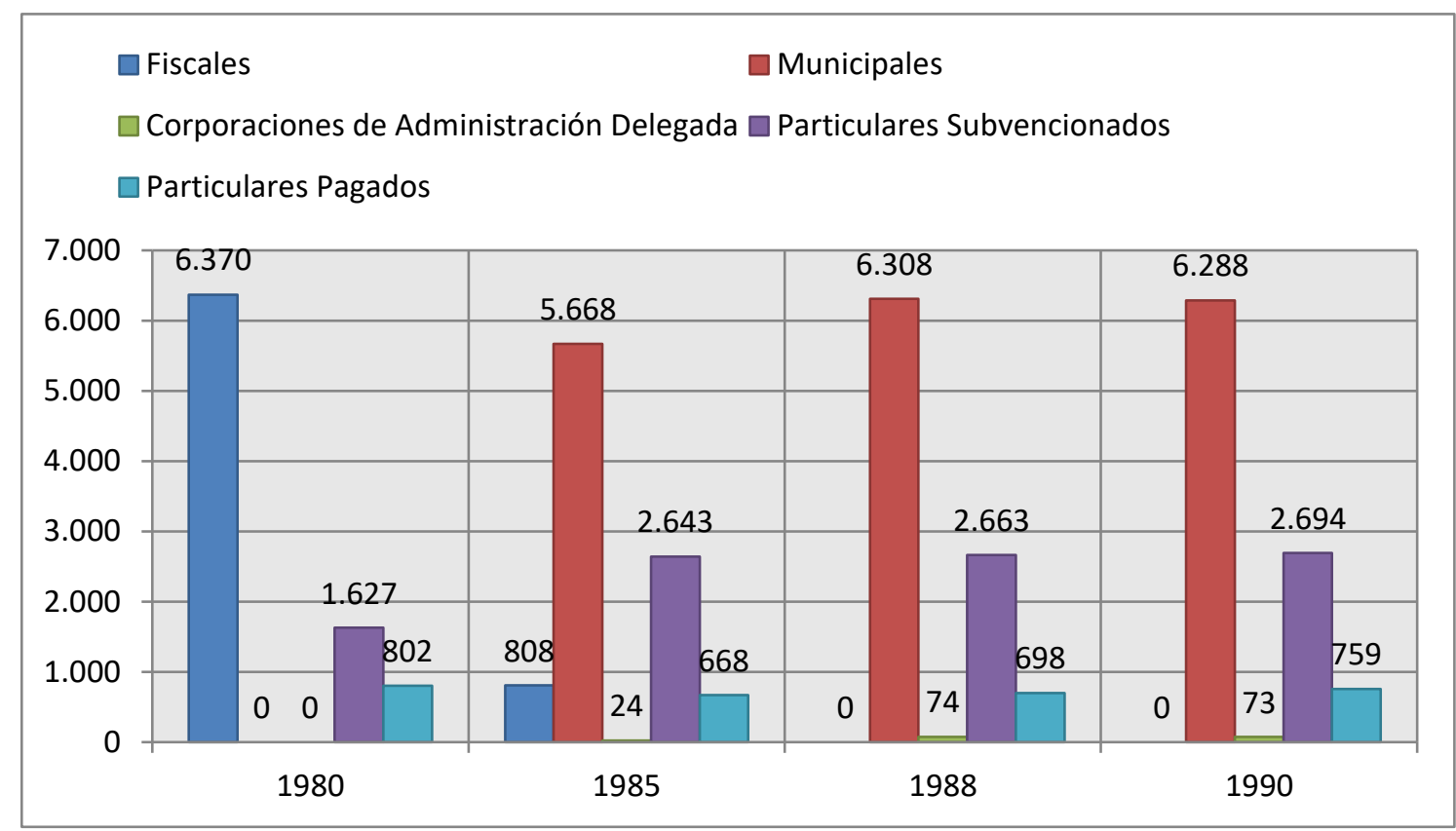

Fuente: MALDONADO, M. La privatización de la educación en Chile. San José: Internacional de la Educación, 2003, 66 p.

En el caso de la Matrícula Escolar, existe una correspondencia con el nuevo panorama de Establecimientos Educacionales, no obstante, al observar el Gráfico $\mathrm{N}^{\circ} 6$ es posible observar una lenta y constante alza de la Matrícula Escolar en Establecimientos Particulares Subvencionados, la que no es necesariamente correlativa con las modificaciones de la cantidad de Establecimientos Educacionales.

GRÁFICO No 6: Matrícula Educación Básica y Educación Media según Dependencia (1981-1990)

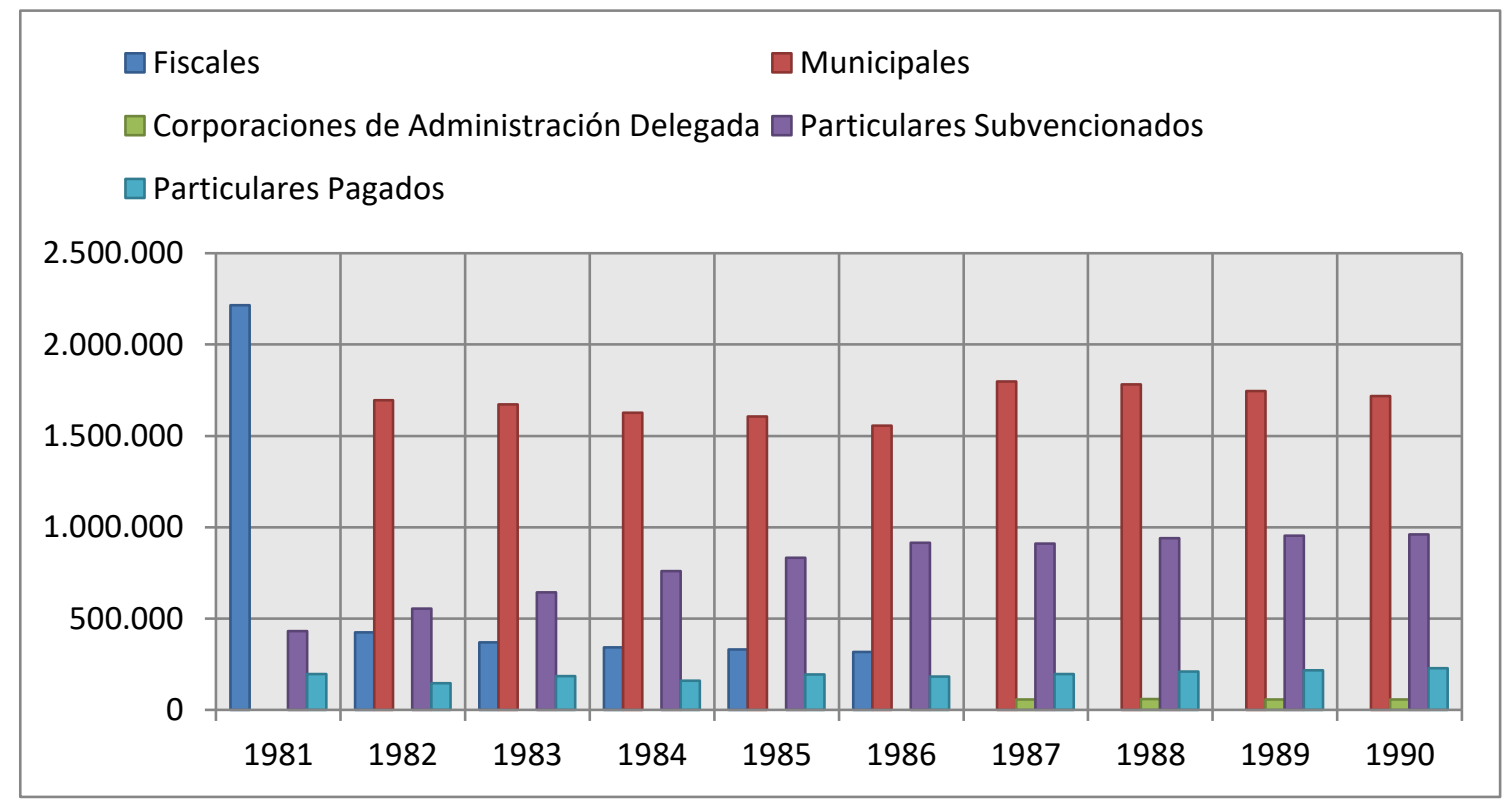

Fuente: MALDONADO, M. La privatización de la educación en Chile. San José: Internacional de la Educación, 2003, 66 p. 
El proceso de Municipalización junto a la nueva modalidad de financiamiento educacional, ayudaron a transformar el panorama del Sistema Escolar chileno, al hacer desaparecer la presencia directa del Estado en la tarea de administrar y gestionar Establecimientos Educacionales, junto con hacer desaparecer la figura del Estado como gran Empleador directo del Trabajo Docente. Con estas Políticas Públicas Educacionales se transformó profundamente el Sistema Escolar como espacio de desempeño laboral y como espacio de estudio. Miles de Establecimientos Educaciones, miles de docentes y millones de estudiantes fueron convidados, forzosamente, a participar de esta gran transformación.

\section{Conclusiones}

Las Políticas Públicas Educacionales de orientación neoliberal diseñadas e implementadas por la Dictadura Militar chilena (1973-1990) ciertamente lograron redefinir el papel del Estado en el campo educacional. Esta redefinición se orientó en la línea del desarrollo de un radical proceso de trasvasije de personas, recursos e iniciativas en diferentes planos educacionales desde el campo estatal hacía el campo privado. Dicho proceso puede ser abordado a partir de las siguientes consideraciones:

Primero, marcó la sustitución de la tradicional figura del Estado Docente por la figura de un Estado Subsidiario, que se asume como un espectador de la realidad social y como un facilitador de grupos de la sociedad civil que buscan formas alternativas para resolver sus necesidades educacionales. Esta nueva figura estatal ayudó a estrechar el espacio público en el campo educacional, fundamentalmente al nombrar al mercado como la arena donde las familias deberían buscar satisfacer sus necesidades educativas. Dicho movimiento legitimó finalmente a la desigualdad como el fenómeno organizador de la relación entre el sistema educacional y la sociedad, coartando de antemano cualquier perspectiva utópica o transformacional asociada al campo educacional.

Segundo, este proceso de transferencia de responsabilidades educativas desde el campo estatal hacía el campo privado fue llevado a cabo en un contexto de ausencia de las mínimas condiciones democráticas de diálogo público y académico, donde fuese posible expresar de manera abierta perspectivas alternativas a la oficiales. De esta forma, la transformación educacional de corte neoliberal en Chile fue signada por un componente autoritario irrefutable. Tal como ha sido abordado en otros trabajos (Zurita, 2015, 2017) fue el Terrorismo de Estado contra la sociedad en general y contra los actores educativos el lenguaje hegemónico en la articulación de la obra educacional de la Dictadura Militar, esto a pesar de los serios intentos por fundamentar la misma en cierto lenguaje técnico/académico.

Tercero, en este proceso de transformación neoliberal del sistema educacional chileno fue el Trabajo Docente unos de los sectores más directamente afectados, puesto que el Profesorado chileno había sido por generaciones el grupo laboral y profesional que había dado vida al Estado Docente a lo largo y ancho del territorio nacional. En las nuevas condiciones generadas por la Dictadura Militar, el aporte del Profesorado ya no era prioritario, puesto que finalmente el sistema educacional en su conjunto había dejado de ser asociado a aquellas diversas perspectivas transformacionales que de una u otra manera habían estado presentes, a lo menos como expectativa, desde el mismo periodo de construcción republicana. 


\section{Referencias}

BERCHENKO, P. Populismo y autoritarismo: alternativas escolares en Chile, 1964-1977. Perpiñán: Universidad de Perpiñán, 1983. 278 p.

CASTRO, P. La Educación en Chile de Frei a Pinochet. Salamanca: Ediciones Sígueme, 1977. 237p.

CHILE. Ley $\mathrm{N}^{\circ} 15.720$ Crea una corporación autónoma con personalidad jurídica y derecho público y domicilio en Santiago, denominada Junta Nacional de Auxilio Escolar y Becas. Ministerio de Educación Pública, Santiago, 01 Octubre 1964. Disponible en: http://bcn.cl/1ngre Consultado en: 14 Julio 2015.

CHILE. Decreto $N^{\circ} 27.952$ Modifica Sistema Educacional. Ministerio de Educación Pública, Santiago, 20 Diciembre 1965. Disponible en: http://ben.cl/1mxwz Consultado en: 14 Julio 2015.

CHILE. Ley $\mathrm{N}^{\circ} 16.617$ Fija escala de categorías, grados y sueldos de los funcionarios que indica. Crea la Corporación denominada Servicio de Bienestar del Magisterio y de los funcionarios dependientes del Ministerio de Educación Pública. Dispone fondos para diversas instituciones. Modifica impuestos. Modifica leyes y decretos con fuerza de ley que señala. Aprueba disposiciones varias. Otras materias. Ministerio de Hacienda, Santiago, 31 Enero 1967. Disponible en: http://bcn.cl/1tryb Consultado en: 14 Julio 2015.

CHILE. Decreto Ley $N^{\circ} 212$ Crea Comisión Nacional de la Reforma Administrativa. Ministerio del Interior, Santiago, 26 Diciembre 1973. Disponible en: http://bcn.cl/1xzup Consultado en: 14 Julio 2015.

CHILE. Decreto Ley N ${ }^{\circ} 575$ Regionalización del país. Ministerio del Interior, Santiago, 13 Julio 1974. Disponible en: http://bcn.cl/1vjwk Consultado en: 14 Julio 2015.

CHILE. Decreto Ley N ${ }^{\circ} 2.093$ Modifica la naturaleza jurídica de la Comisión Nacional de Reforma Administrativa y fija planta de su personal. Ministerio de Hacienda, Santiago, 04 Enero 1978. Disponible en: http://bcn.cl/1xzur Consultado en: 14 Julio 2015.

CHILE. Decreto Ley $N^{\circ} 2.868$ Divide las Provincias que señala del país en las Comunas que indica. Ministerio del Interior, Santiago, 26 Octubre 1979. Disponible en: http://bcn.cl/1w01b Consultado en: 14 Julio 2015.

CHILE. Decreto Ley $\mathrm{N}^{\circ} 3.166$ Autoriza entrega de la administración de determinados Establecimientos de Educación Técnico Profesional a las instituciones o a las personas jurídicas que indica. Ministerio de Educación Pública, Santiago, 06 Febrero 1980. Disponible en: http://bcn.cl/12sh Consultado en: 14 Julio 2015.

CHILE. Decreto con Fuerza de Ley $\mathrm{N}^{\circ}$ 1-3063 reglamenta aplicación inciso segundo del artículo $38^{\circ}$ del DL No 3.063, de 1979. Ministerio del Interior, Santiago, 13 Junio 1980. Disponible en: http://bcn.cl/pmd Consultado en: 14 Julio 2015.

CHILE. Decreto Ley $\mathrm{N}^{\circ} 3.476$ Fija normas a los establecimientos de enseñanza particular subvencionados por el Estado. Ministerio de Hacienda, Santiago, 04 Septiembre 1980. Disponible en: http://bcn.cl/1xivg Consultado en: 14 Julio 2015. 
CHILE. Decreto Supremo N ${ }^{\circ} 1.150$ Constitución Política de la República de Chile. Ministerio del Interior, Santiago, 24 Octubre 1980. Disponible en: http://bcn.cl/1wb8d. Consultado en: 14 Julio 2015.

CHILE. Ley $N^{\circ} 18.575$ Orgánica Constitucional de Bases Generales de la Administración del Estado. Ministerio del Interior - Subsecretaria del Interior, Santiago, 05 Diciembre 1986. Disponible en: http://bcn.cl/1uvo7. Consultado en: 14 Julio 2015.

CONARA. Políticas de la Comisión Nacional de Reforma Administrativa, CONARA. Santiago: CONARA, 1981, 33 p.

COX, C.; JARA, C. Datos básicos para la discusión de políticas en educación. 1970-1988. Santiago: CIDE / FLACSO, 1989. 74 p.

DÍAZ, J.; LÜDERS. R.; WAGNER, G. Chile 1810 - 2010. La República en cifras. Historical statistics. Santiago: Ediciones Universidad Católica de Chile, 2016, 780 p.

ESPINOZA, O; GONZÁLEZ, L. La experiencia del proceso de desconcentración y descentralización educacional en Chile 1974-1989. Santiago: PIIE, 1993, 267 p.

FUNDACIÓN SOL. Reforma Laboral. ¿Pone fin al Plan Laboral de la Dictadura o lo consolida? Infórmate, debate, propone. Santiago: Fundación Sol, 2015. 41 p.

GONZÁLEZ, F. La educación de masas, por las masas y para las masas: El programa de la Unidad Popular y la escuela como espacio de lucha política. Pacarina del Sur. Revista de Pensamiento Crítico Latinoamericano. México D. F., n 17, Octubre-Diciembre 2013.

GONZÁLEZ, F.; OSANDÓN, L. La educación de masas durante la Unidad Popular: una nueva escuela para toda la comunidad. In: PINTO, J. Fiesta y drama. Nuevas historias de la Unidad Popular. Santiago: LOM, 2014. p. 109-142.

LEYTON, M. La experiencia chilena: la reforma educacional: 1965-1970. Santiago: CPEIP, 1970. 417 p.

MALDONADO, M. La privatización de la educación en Chile. San José: Internacional de la Educación, 2003, 66 p.

NÚNEZ, I. Cambios en la situación del magisterio. Santiago: PIIE, 1982. 81 p.

NÚÑEZ, I. Reformas educacionales e identidad de los docentes. Chile, 1960-1973. Santiago: PIIE, 1990. 251 p.

NÚÑEZ, I. La ENU entre dos siglos. Ensayo histórico sobre la Escuela Nacional Unificada. Santiago: LOM, 2003. 144 p.

PIIE. Las Transformaciones Educacionales bajo el Régimen Militar. (2 volúmenes). Santiago, Chile: Programa Interdisciplinario de Investigación en Educación, 1984. 652 p.

PINOCHET, A. Directiva presidencial sobre la educación nacional. Separata publicada en Cuaderno del Profesor Rural, Santiago, n. 17, p. I-VIII, mayo-junio 1979. 
ROJAS, P. Remuneraciones de los profesores en Chile. Estudio Públicos, Santiago, n. 71, p. 121-175, 1998.

SERRANO, S; PONDE DE LEÓN, M; RENGIFO, F. Historia de la Educación en Chile (1810-2010). Tomo I Aprender a leer y escribir (1810-1880). Santiago: Taurus, 2012. 397 p.

ZURITA, F. Violencia, poder político y políticas públicas educacionales: el trabajo docente bajo la dictadura militar en Chile (1973-1990). Revista Teoria e Prática da Educação, v. 18, n. 1, p. 89-100, 2015.

ZURITA, F. (2017). Represión y vigilancia hacia el Trabajo Docente durante la Dictadura Militar en Chile (1973-1990). Araucaria. Revista Iberoamericana de Filosofía, Política y Humanidades, v. 19, n. 38, p. 285-322, 2017. 